\title{
La(s) lectura(s) en la obra de Manuel Vicent: biografía literaria e imagen de autor
}

Solía Bonino

Recebido em: 12 de janeiro de 2020

Aceito em: 11 de março de 2020
Solía Bonino es Profesora en Letras por la Universidad Nacional de La Plata. Actualmente está cursando el Doctorado con orientación en Literatura Española. Desde 2012 colabora en la cátedra de Literatura Española B de la FaHCE y participa de proyectos de investigación en el área, tarea que complementa con la publicación de artículos y la asistencia a congresos.

Contato: boninosofia.unlp@gmail. com

Argentina 
PALABRAS CLAVE: Lectura; biografía literaria; canon; Manuel Vicent

KEYWORDS: Reading; literary biography; canon; Manuel Vicent
Resumen: Este trabajo busca realizar una reconstrucción de la biografía literaria de Manuel Vicent a partir de dos novelas: Verás el cielo abierto y Tranvía a la Malvarrosa y de una selección de artículos periodísticos que tematizan la lectura y vuelven a aquellos autores que han sido pilares en la formación literaria del autor. Tanto los textos ficcionales como los artículos que incluyen el tema de la lectura y de la formación literaria confluyen en la conformación de una imagen de escritor cuyas huellas se pueden rastrear en su estilo y trayectoria. En la biografía literaria de Vicent coinciden las obras canónicas con géneros tradicionalmente considerados marginales. La elección de definirse como hombre de letras y como escritor desde el periodismo va en sintonía con la imasen de autor que va creando desde sus novelas autobiográficas y sus artículos.

Abstract: This work seeks to make a reconstruction of the literary biography of Manuel Vicent from two novels: Verás el cielo abierto, Tranvía a la Malvarrosa and a selection of journalistic articles that thematize reading and return to those authors that have been pillars in the literary formation of the author. Both fictional texts and journalistic articles that include the subject of reading and literary training come together in the conformation of an image of a writer whose steps can be traced in his style and career. In the literary biography of Vicent, canonical works coincide with genres that have traditionally been placed on the sidelines. The choice of defining oneself as a man of letters and as a writer since journalism is in tune with the author's image that he is creating from his autobiographical novels and articles. 
¿Cómo conformar una historia de la lectura? Lyons (2012) dice que la misma debería responder a preguntas tales como qué se leía en una sociedad dada, quién leía y cómo leía. Para Lyons, interesan menos los lectores implícitos (aquellos que están “ocultos” en cada fragmento de literatura, aquellos que intentaban encontrar los exponentes de la Teoría de la recepción) que los lectores reales. El interés de un historiador de la literatura no está "en las implicaciones de los textos canónicos fosilizados en el tiempo, sino en los lectores de carne y hueso inmersos en circunstancias históricas específicas" (Lyons, 2012, 21). ¿Dónde es posible encontrar testimonio de estas prácticas? Los lectores reales han dejado registro "en sus propias autobiografías, cartas, diarios" (Lyons, 2012, 21). Esos textos, entonces, se convierten en insumos fundamentales para pensar la historia de la lectura.

Por otro lado, la respuesta a cómo se lee puede y debe ir más allá de la asignación de significados a lo escrito. Debe incluir elementos vinculados a la materialidad del texto, la posición corporal, la lectura silenciosa o en voz alta, entre otros (Chartier, 2006). De ese modo es posible establecer relaciones entre la lectura como práctica puramente intelectual y los diferentes modos de relacionarse con lo escrito a lo largo de la historia desde el punto de vista físico, corporal, y desde el punto de vista material: qué soporte vehiculiza la lectura y cómo influye ese soporte en el proceso de asignación de significado.

En relación al concepto de imagen de escritor, partiremos de la premisa de María Teresa Gramuglio que afirma que "los escritores, con gran frecuencia, construyen en sus textos figuras de escritor y que estas figuras suelen condensar, a veces oscuramente, a veces de manera más o menos explícita 
y aún programática, imágenes que son proyecciones, autoimágenes y también anti-imágenes o contrafiguras de sí mismos (Gramuglio, 1992, 37). La conformación de un “itinerario de lector”, en el caso de Manuel Vicent, no solo puede ayudar a esclarecer ciertas prácticas de lectura en general, sino también aportar a la conformación de una figura de escritor en los términos que, esperamos, dejaremos planteados a continuación.

Para ello, trabajaremos principalmente con dos novelas del autor y se complementará el análisis con una selección de artículos de periódico. El denominador común de los escritos elegidos es la tematización de la lectura desde diferentes perspectivas: el descubrimiento de la lectura y del libro, los modos de leer, las lecturas prohibidas y las lecturas obligadas, la lectura y su relación con la escritura. Consideramos que la confluencia de estos elementos da lugar a la conformación de una imagen de autor con ciertas particularidades que la alejan de los parámetros convencionales pero que no deja de evidenciar un fuerte vínculo con el canon del siglo XX.

Manuel Vicent tiene una serie de novelas ${ }^{1}$ que podrían considerarse autoficcionales $^{2}$. Las dos obras que se analizarán en este trabajo Verás el cielo abierto y

1 Además de la trilogía formada por Contraparaíso (1993), Jardín de Villa Valeria (1996) y Tranvía a la Malvarrosa (1994), la crítica incluye en la serie autoficcional Verás el cielo abierto (2005), León de ojos verdes (2008), Comer y beber a mi manera (2006) y su Clase magistral Travesía literaria (2017).

2 Manuel Alberca, en su artículo dedicado a Vicent ha definido la autoficción como “...una novela o relato que se presenta como ficticio, en el que el autor manifiesta una evidente determinación de novelizar su vida, y en el que, además, como signo evidente de dicha intención, el narrador/ protagonista comparte el mismo nombre propio con el autor, estableciéndose así una inequívoca relación identitaria entre ambos (...). Así pues, una autoficción, aunque es una novela o se presenta como tal, parece una autobiografía y bien podría serlo, pero también podría ser su 
Tranvía a la Malvarrosa pertenecen a este ciclo; sin embargo, como veremos, el modo de vincularse con la materia narrativa no es el mismo. En Tranvía a la malvarrosa el protagonista es Manuel, un adolescente que comienza a descubrir el mundo y a forjar su identidad mientras se aleja de las imposiciones familiares, especialmente del mandato paterno. Verás el cielo abierto nos presenta, también, la etapa de la infancia y juventud de Manuel, pero la perspectiva es la de un hombre ya maduro, melancólico y que se cree próximo a la muerte.

Los artículos periodísticos complementan este recorrido. En la antología Póquer de ases se reúnen textos, anteriormente publicados en prensa, en los que el autor "retrata" a aquellos hombres que fueron fundamentales en su historia de lector y escritor, pero también de la historia de la lectura y la escritura contemporáneas. El artículo "La literatura y la lectura como obras de arte" publicado en el suplemento Babelia (1996) del diario El País, a su vez, forma parte de un ciclo de publicaciones llamado "Mis lecturas" que salió durante un año. En este artículo, Vicent selecciona a aquellos autores que fueron marcando sus diferentes etapas de lector, describe los modos en los que se acercaba a la literatura y, también, nos dice qué le gusta leer y qué no.

Si pensamos en las escenas de lectura descriptas en las novelas ${ }^{3}$ de Manuel Vicent podremos observar que esta actividad está planteada como un acto

simulación..." (Alberca, 2008, 200). Alberca ha trabajado con el tema de manera más extensa en El pacto ambiguo. De la novela autobiográfica a la autoficción (2007).

3 El componente biográfico de las novelas mencionadas resulta innegable, pero no es posible hablar limpiamente de autobiografías, consideramos más adecuado el término autoficción. Gerardo Balverde ha afirmado que, en estas novelas, el autor invita a pensar sus obras como memorias que incluyen al individuo situándolo en la perspectiva de lo colectivo, lo generacional $(2008,236)$. 
multidimensional, en el que no se destaca únicamente el componente intelectual sino también lo corporal, lo sensorial. Asimismo, el libro, para Vicent, no es un mero transmisor de significados, sino un objeto en el que se destaca la materialidad, la organización física (Chartier, 2006). La situación de lectura es una "ocasión para el sentimiento"4 en términos de Littau (2006, 19); el autor destaca las sensaciones previas, la estimulación sensorial ligada al acto de lectura, lo postural, los efectos emocionales de determinados textos.

El componente corporal, físico, material y sensorial de la lectura, usualmente desatendido y minimizado, es puesto en foco por el autor, especialmente cuando se refiere a sus primeras lecturas. En "La literatura y la lectura como obras de arte" (1996) Vicent menciona el hallazgo del primer libro que conformó su biblioteca, objeto encontrado en el cadáver de un soldado; el libro, Corazón de Edmundo d'Amicis, tenía los cantos podridos, por lo que él debía suplir con la imaginación los fragmentos ilegibles. También resulta interesante la elección formativa de este texto en relación a la trayectoria del escritor. En este sentido, Raquel Macciuci sostiene que es significativo que el segundo libro de la biblioteca sea Lo que puede más que el hombre, escrito por Emilio Gómez de Miguel, regalo de un maestro e inscripto en el campo de la pedagogía. Se trata de un libro de divulgación científica, acerca del

4 La expresión que tomamos de Littau requiere ciertas aclaraciones, la autora se refiere, cuando habla de "ocasión para el sentimiento", al modo en que antiguamente la lectura afectaba al cuerpo del lector provocando diferentes efectos (lágrimas, carcajadas, nerviosismo). Dice Littau: "La historia que reseńo en este libro señala una escisión entre los estudios literarios modernos, que tienden a considerar la lectura como una actividad reductible a la esfera mental, y una tradición que data de la Antigüedad y que suponía que leer literatura no implicaba solamente comprensión sino también sensaciones" $(2006,20)$ 
poder de la ciencia y la razón para combatir la ignorancia. Estas dos obras, uno con forma de diario íntimo y otro sobre ciencia, dicen mucho sobre un escritor asociado al soporte prensa, ligado al fragmentarismo de los géneros breves y no canónicos y al rigor informativo, premisa básica de un escritor periodista (Macciuci, en prensa).

A partir de este relato podemos ver, por un lado, que el inicio de la biblioteca personal no viene de la escuela ni de la familia sino de zonas marginales, descentradas con respecto a la educación impuesta. El libro es hallado en el ámbito de la libertad si pensamos en la oposición planteada por el mismo Vicent respecto de su casa y "el afuera” a la que se hará referencia más adelante; por lo tanto, el hallazgo se convierte en parte de ese ejercicio de libre albedrío, exento de las imposiciones familiares y evidencia la inversión de las elecciones formativas desde el punto de vista del niño. A su vez, el escritor adulto, que elige esta anécdota para marcar el inicio de su formación como lector está deconstruyendo los espacios validados de la cultura e invitándonos a leer por fuera de los ámbitos legitimados. Los primeros libros, las primeras lecturas escogidos como representativos son marginales -los tebeos- o hallados en los márgenes- Corazón ${ }^{5}$.

Por otro lado, este primer libro, que despierta su imaginación y que se convierte en un objeto preciado, es encontrado en un cadáver y es la podredumbre del libro la que lo obliga a crear. Frente al libro como objeto preciado, resguardado, preservado, él destaca este hallazgo derruido, en el

5 Raquel Macciuci, en su estudio preliminar de la novela Contra Paraíso se detiene en esta cuestión. (Macciuci, en prensa) 
cual, el mensaje está interferido por la descomposición de las páginas y ese deterioro es el disparador de la creación.

El lugar privilegiado que ocupan los tebeos en la biografía del autor viene a reafirmar la revalorización de aquello tradicionalmente considerado secundario. En Verás el cielo abierto menciona su afición a las historietas como una obsesión. Allí describe la espera de la llegada del tren que las llevaba al pueblo y la ansiedad ante el retraso "... que yo asimilaba a lo difícil que es ser feliz...” (66). En el momento de comenzar la lectura, se destacan las sensaciones previas y la situación es descripta como un ritual: "Primero olía profundamente la portada de colores, la respiraba hasta el alma y el olor de la tinta de linotipia era tan intenso que a veces me dejaba a punto de desmayarme" (67). Estas lecturas también incentivaban la imaginación de Manuel: "Aquellos tebeos eran mi sueńo, mi forma de volar, el único sustento de mi imaginación. Los leía tumbado en el suelo, boca abajo...”. (68)

El carácter marginal del género, los prejuicios respecto a los posibles efectos nocivos de ciertas lecturas, incluso la interpretación de lo postural, del modo de leer, desembocan en una escena de enojo paterno, quien termina destrozando las historietas y colocando sus hojas como papel higiénico "porque me estaban sorbiendo el seso" (Vicent, 2005, 173). Manuel siente que esto es una humillación para aquel objeto de adoración y lleva a cabo un minucioso trabajo de rescate; luego realiza un sacrificio con aquellos restos (los quema) para salvarlos de la deshonra. En esta escena, nuevamente se reposiciona aquello que se ubica en los límites de la cultura y se le da a la historieta el lugar del libro como objeto valorado, preciado, legitimado 
y, por lo tanto, digno de ser censurado y destruido por ser potencialmente peligroso. El niño ubica a estas revistas en un lugar encumbrado, su padre las considera un entretenimiento perjudicial, que distrae de lo importante, pero a su vez les otorga valor al colocarlas como objeto de censura.

La preocupación por la moral cristiana es una de los motivos de desaprobación de su padre. Manuel será el elegido para seguir la carrera eclesiástica y la lectura aparecerá como un elemento de distracción y desvío del camino impuesto. Una de las escenas más representativas en este sentido será la recreación de uno de los episodios más memorables de Don Quijote de la Mancha: el escrutinio de la biblioteca. De modo paródico se introduce en Verás el cielo abierto el momento en la que su padre, un cura y un farmacéutico clasifican una serie de libros de la colección Austral que Manuel, adolescente, había encargado a la editorial Espasa Calpe respondiendo a un momento pasional de lectura voraz. El pedido cae en manos de su padre, que recurre al párroco y al farmacéutico para tomar una decisión definitiva sobre los libros. El criterio de selección es puramente religioso y por ello es el cura el que tiene la última palabra (aunque, claramente, es más ignorante que el farmacéutico). El cura y el padre pretenden prohibir cualquier tipo de lectura anticlerical, pero la ignorancia de ambos le quita sentido a la clasificación: "De Baroja solo se salvó un libro porque llevaba un crucifijo en la portada y el título Camino de perfección, tal vez recordaba el cura algún tratado de ascética, siendo como era entre todas las novelas de Baroja la más irreligiosa ${ }^{\text {") }}$ (Vicent, 2005, 93).

6 El título del libro de Baroja coincide con el de una obra de Santa Teresa, sin embargo, el camino del personaje barojiano es irónico. En este sentido Raquel Macciuci dice: "Si el camino de perfección 
El autor, en este juego de realidad-ficción que crea en sus novelas con contenido autobiográfico, lleva al extremo la severidad paterna, el absurdo de la reprobación y la censura para contraponer un "afuera" donde se encuentra esa libertad ańorada. Los episodios en los que el padre reprueba el comportamiento de Manuel contrastan con aquellos en que la lectura oficia como válvula de escape y espacio de liberación.

Mónica Musci habla de "escenas en que los personajes, al apropiarse de textos o de fragmentos de textos, logran elaborar un espacio de libertad a partir del cual dan sentido a sus vidas o encuentran energías suficientes para escapar de situaciones de angustia" (2014,3). Si bien en este texto hace referencia a las situaciones de reclusión propias de la guerra civil y el franquismo, es posible pensar de esta manera la contraposición "adentro-afuera" planteada por Vicent en Verás el cielo abierto, donde el adentro está marcado por una educación estricta que representa para el narrador un encierro, y el afuera, donde encuentra la libertad que la educación franquista le arrebata. El elemento que permite el pasaje es la puerta, motivo recurrente en esta novela: una puerta de madera que "dividía en dos mi imaginación" y que "al traspasarla el mundo cambiaba" (165). También la lectura oficia como puerta: "Las aventuras de Julio Verne me aceleraban los latidos de la sangre (...) pero yo solo lloraba de emoción con los relatos de aventuras, con los cuentos de oro, con los libros de la selva o perdido en las islas del tesoro llenas de piratas y bucaneros. Era la edad de mi inocencia literaria." (Vicent, 1996)

es un camino hacia la experiencia mística, debemos pensar que el título de Baroja está cargado de una ironía y un distanciamiento mordaz del discurso religioso.” (Macciuci, 2002, 212) 
Estos primeros vínculos con lo escrito vehiculizan una doble rebeldía: ante el mandato familiar y ante las imposiciones literarias. La infancia y la adolescencia serán etapas de lectura apasionada, corporal, identificada, en muchas ocasiones, con la enfermedad o con el apetito: "yo leía como un tuberculoso sin estarlo" (Vicent, 1996) o "en ese tiempo yo había desarrollado un hábito de lectura que llegaba a la voracidad. Leía todo lo que caía en mis manos" (Vicent, 2005, 90). Es por eso que Vicent refiere cada episodio describiendo detalladamente en el lugar, la postura y las sensaciones suscitadas por el acto de leer. Otro ejemplo es la lectura de Camino de perfección:

Recuerdo que comencé a acariciar el volumen en cuya portada de color marrón había una especie de altar con un crucifijo. Le pasaba la palma de la mano por el lomo, recorría con la yema de los dedos cada una de las letras de su título (...) y después olía los entresijos de sus páginas que exudaban un olor de miel apolillada. (Vicent, 2005, 82)

En la novela, encontramos varias referencias similares a la anterior en las que el momento de lectura es protagonista. En ellas, se menciona el lugar, la posición corporal e, incluso, los aromas del ambiente, que luego se confundirán con lo leído en el recuerdo: "El olor del tebeo se unía al de los pimientos asados y las patatas fritas" (67); "yo estaba leyendo sentado en la mecedora del balcón el Fausto de Goethe...” (98); “...o leía tumbado en la cama, a Sartre, a Gide, a Camus, y sońaba con ser escritor...” (120); “...me pasaba el día leyendo tumbado en la cama hasta que mi amigo Vicentico Bola se mató con la moto...” (157). 
En el artículo "La literatura y la lectura como obras de arte" Vicent establece un cambio en el modo de lectura a partir del fin de la pubertad, identificado con la "pérdida de la inocencia literaria". Las formas de leer durante la infancia están fuertemente marcadas por lo corporal, la lectura en este período se caracteriza por generar efectos en el cuerpo, sensaciones que quedan en el recuerdo y se mezclan con el contenido de las lecturas.

En la novela Tranvía a la Malvarrosa se relata el período de transición entre la infancia, de lectura inocente, y la adultez, de lectura, en sus palabras, "agnóstica". En esta obra, el personaje comienza la búsqueda de la verdadera identidad. Esta determinará el alejamiento de la religión, el deseo de ser escritor y, especialmente en esta novela, el descubrimiento del amor romántico y del sexo. Desde este punto de vista, esta novela puede considerarse "de formación"', y el resultado es el conocimiento de sí mismo. La lectura en la adolescencia, voraz, como un apetito difícil de saciar, se alterna con el descubrimiento de otras formas de placer y con la ruptura con el sistema de valores inculcado por la familia y la escuela.

Luego del recorrido heterodoxo que se inicia con Roberto Alcázar y con Corazón, la biblioteca personal que se conforma es canónica y clásica, pero ese inicio permite considerar que no es el resultado solo de lo que "debe" leer -ya que afirma haber leído, también, lo que el canon imponía- sino del

7 De Diego define la novela de aprendizaje o de formación como "un tipo de novela: a) en la que se narra el desarrollo de un personaje -generalmente un joven-a través de sucesivas experiencias que van afectando su posición ante sí mismo, y ante el mundo y las cosas; por ende, el héroe se transforma en un principio estructurante de la obra; b) que cumple -o busca cumpliruna función propedéutica, ya sea positiva -modelo a imitar- o negativa -modelo a rechazar-, independientemente de la mayor o menor presencia de la voz autoral”. (De Diego, 2007, 293) 
gusto y de la experiencia lectora, de un itinerario escogido. Hay, entonces, un acercamiento al canon pero rescatando, al mismo tiempo, las lecturas que más influyeron durante la nińez y con las que se ha formado como lector.

El recorrido que el personaje lleva a cabo en Tranvía a la Malvarrosa y sus aprendizajes, dan lugar a esas lecturas más ortodoxas pero igualmente significativas y provechosas. Aquí, el acto de leer es formativo y, por eso, la lectura, en esta etapa, tendrá la función fundamental de acompañar el crecimiento del joven y la transformación en adulto.

Pío Baroja funciona como nexo entre la infancia y la juventud, y la importancia de este se corrobora al leer el retrato que incluye en Póquer de ases: "Este hecho me impulsó a leer a Baroja a edad muy temprana y fue Camino de perfección la primera de sus novelas que cayó en mis manos, lo que me produjo una excitación extraordinaria porque la leí en clandestinidad saboreándola como un pecado." (Vicent, 2009, 268). Baroja será, inicialmente, una figura misteriosa, el huésped siempre esperado por la familia Ranch (vecinos de la infancia) ${ }^{8}$. A su alrededor Vicent creará una especie de mito, alimentado por una visita que nunca se realiza. La ausencia de "Don Pío", finalmente, será más fructífera que su presencia. La entrada a la habitación nunca ocupada por Baroja le permite soñar, por primera

8 Vicent cuenta en Verás el cielo abierto la historia de Eduardo Ranch (un músico de familia acomodada) y su obsesión por convertirse en un personaje barojiano primero y por el propio Baroja después. Esta obsesión lo llevará luego a un intercambio epistolar con el escritor. En una de esas cartas, Ranch invitará a Baroja a su casa solariega de Villavella -pueblo natal de Manuel Vicent-y la espera y la expectativa por la llegada de "Don Pío" atravesarán el pueblo, al punto de quedar en el recuerdo del pequeño Manuel. La visita no llegará a concretarse y quedará, en la casa de los Ranch, una habitación destinada al invitado que se convertirá en una especie de santuario. 
vez, con la posibilidad de ser escritor: "Baroja no había entrado nunca en esa habitación, en cambio yo finalmente lo había conseguido ¿Por qué no me atrevía a suplantarlo? Todos mis sueños de escritor se agolparon en mi mente" (Vicent, 2005, 101).

Más tarde sumará a sus lecturas a Camus, Unamuno, Goethe, Ortega y Gasset, Gide, Sartre, Thomas Mann. Al relatar estas incorporaciones elabora un itinerario geográfico que lo lleva desde España hacia el resto del mundo: "A los 18 me adentré por la ruta de Baroja. Luego estuve con Sartre, Gide y Camus en el barrio Latino tomando huevos duros en el Flore. Después me pasé desde el Misisipí a Dublín, a San Petersburgo, a Praga, a Edimburgo” (Vicent, 1996). Estos autores acompañarán el proceso de creación de un proyecto personal e irán creando en el protagonista un sistema alternativo de valores que reemplazará, poco a poco, el que estaba arraigado desde la formación escolar y familiar: el católico conservador.

En esta obra también encontramos referencias que igualan la lectura a la alimentación: "Yo solo quería encontrar a Marisa en una de las calles de Valencia y seguir devorando más libros de Albert Camus, al que acababa de descubrir en la trastienda prohibida de la librería Rigal"9 (Vicent, 2014, 120); "había comenzado a embriagarme con El inmoralista de Gide" (Vicent, 2014, 125). Y, nuevamente, la lectura está estrechamente ligada a la atmósfera

9 Los libros editados en América -especialmente en México y Argentina que supieron aprovechar el declive de la industria editorial española y la mano de obra de cantidades de exiliados españolesllegaban a España luego de sortear una serie de obstáculos burocráticos y de censura. Los libros prohibidos que lograban llegar a la trastienda de alguna librería se ofrecían clandestinamente y a precios muy superiores a cualquier libro editado en España y/o que tuviera la aceptación del organismo censor. En relación a este tema ver: Martínez Rus, 2016. 
en la que se lee, a lo sensorial, como un elemento más que, al igual que un aroma, que un sabor, estimula los sentidos y, a través de esa estimulación, deja marcas: "La espiritualidad era el azahar, el perfume que hacía que te levantaras con dolor de cabeza, y dentro de esa atmósfera también leía los libros de Ortega y Unamuno con la colección Austral” (Vicent, 2014, 127); "Aquel verano en el balcón de casa leía libros de Austral, las Noches florentinas de Heine, todo lo de Ortega y Gasset, La montaña mágica, los cuentos de Andreiev (...) y aquellas lecturas estaban como siempre oreadas por la brisa del corredor que agitaba las cortinas". (Vicent, 2014, 130)

Encontramos varios pasajes en la novela en los que se evidencia cómo el personaje va a conociendo aquellos autores y textos que lo marcan y que funcionan como puerta de entrada a una nueva forma de relacionarse con la realidad. En estos pasajes, aún se puede entrever la inocencia de la lectura adolescente, pero también se vislumbra el adulto lector y el escritor.

Como dijimos, los textos escogidos en este período van a acompañar el proceso de alejamiento de la religión. La novela se abre con el temor a la pérdida de la pureza, de la inocencia y con el miedo frente al pecado y el castigo en el episodio en que Vicentico Bola oficia de "tutor" para la iniciación sexual. Ese temor a dios se transformará luego en una inocencia "sin dios": "También leía a León Bloy y a Romano Guardini. pero en una capa inferior del cerebro palpitando llevaba siempre la imagen de Marisa y con ella el nuevo descubrimiento de la inocencia sin Dios, el sentido de la dicha como una nueva moral" (Vicent, 2014, 121). La lectura de Bloy y Guardini, cuyas obras reflejan una devoción profunda hacia la iglesia 
católica, no impide que, paulatinamente, Marisa, el amor platónico de la adolescencia, vaya ocupando el lugar de la pureza que antes ocupaba la religión. Esa "moral de la dicha" apunta a un nuevo parámetro que se va forjando en este proceso de aprendizaje y formación.

La lectura forma parte de esta conversión. Podemos verlo, en primer lugar, por ciertos textos que aparecen como fundacionales en este crecimiento:

Leía un libro de tapas rojas, Verano de Camus, donde estaba mi nueva profesión de fe, que era Nupcias en Tipasa ${ }^{10}$. Por primera vez tenía la percepción del libertinaje de la naturaleza que era todo el mar extendido al pie del trampolín. (Vicent, 2014, 130)

La importancia de Camus en la formación del lector, del escritor y del hombre se reafirma en la antología Póquer de ases. Este volumen se abre con un artículo dedicado a del autor de La peste, allí regresa a los encuentros iniciáticos con el argelino que ratifican el influjo de las lecturas en la conformación del adulto "gozador de placeres efímeros":

A mis dieciocho años, un librero de Valencia me ofreció envuelto en un papel de estraza, por debajo del mostrador, clandestinamente, el libro de Camus de tapas rojas titulado El verano, impreso en Argentina ${ }^{11}$, que leí en

10 En relación a este texto de Camus, dice Gerardo Balverde: "En sus obras autoficcionales Manuel Vicent menciona a menudo un libro específico de Albert Camus, Verano, del cual resalta "Nupcias en Tipasa", suerte de ensayo en el que se exalta el disfrute del mar, la playa, el sexo, la luz solar como una profesión de fe en la que la dicha y la inocencia prevalecen por sobre toda preocupación. Las profundas coincidencias entre el escritor valenciano y francés se materializan en posturas coincidentes, verificables en los personajes de sus ficciones, y que combinan un hedonismo y un epicureísmo conjugados en justas dosis, que amerita un estudio más detenido y profundo." (Balverde, 2008, 9)

11 Ver nota 6. 
la hamaca bajo el sonido de las chicharras y el olor a pinaza abrasada por la canícula. En sus páginas descubrí que el Mediterráneo no era un mar, sino una pulsión espiritual, casi física, la misma que yo sentía sin darle nombre: el placer contra el destino aciago, la moral sin culpa y la inocencia sin ningún dios. (Vicent, 2009, 16)

También en Verás el cielo abierto destaca la importancia de Camus en este sentido: "A los diecisiete años vi una fotografía de Albert Camus ${ }^{12}$ (...). Fue una revelación. Camus me enseñó a encontrar en la pulsión de los sentidos una nueva forma de moral, de inocencia, de belleza” (Vicent, 2005,142).

En Tranvía a la Malvarrosa vemos cómo se va conformando la elección del goce, de la dicha, como una nueva moral. En esta transformación la lectura cumple un rol esencial; esto se confirma, como punto de llegada, hacia el final de la novela:

Hasta ese momento yo había tenido en el cerebro un Dios que había usado como trono el ceńo adusto de mi padre y su dedo implacable para seńalarme el buen camino o fulminarme. Ahora Dios lentamente se iba convirtiendo en el instante de los sentidos y en ese preciso momento eran Dios las volutas del cigarrillo Pall Mall teniendo a Julieta a mi lado... (Vicent, 2014, 203)

En Verás el cielo abierto, numerosos pasajes confirman y refuerzan lo apuntado anteriormente: "Había dejado de ser un elegido de Dios y a partir de aquel día pasé a ser un elegido por Ortega y Gasset, y como primer paso para pertenecer a la minoría selecta contra la revolución de las masas me compré una gabardina blanca de canutillo" (130); "Hasta entonces había leído

12 El lugar destacado que ocupa Camus en la formación de Manuel Vicent como lector y como escritor vuelve a reafirmarse en Travesía literaria (2017). 
a Unamuno, a Ortega, a Baroja, a los tres enemigos del alma. Unamuno me había invitado a leer ahora a Dios en una niebla escandinava, Ortega trató de enseñarme a posar intelectualmente como un señorito" (142).

La idea de lectura clandestina está presente desde el comienzo de la formación del lector y continúa luego. En el caso de Baroja, la novela Camino de perfección, lectura adolescente, se lee a escondidas de la censura paterna; en el caso de Camus, la adquisición de Verano tiene lugar "por debajo del mostrador"; en este caso la censura ya no es la paterna sino la proscripción de la dictadura franquista. En Tranvía a la Malvarrosa acudimos a una incipiente toma de conciencia sobre la realidad política de esos años. La figura de Franco forma parte del escenario que Manuel encuentra al llegar a Valencia: "Franco y yo llegamos a Valencia el mismo día” (Vicent, 2014, 69), y comienza a tomar una forma definida a través de ciertas experiencias de iniciación:

Yo carecía de conciencia política. Franco para mí no era un dictador sino un gordito anodino al que parecían gustarle mucho los pasteles, con aquellas mejillas blandas, el bigotito, la barriguita bajo el cincho, las polainas de gallo con la voz meliflua, el gorro cuartelero, la borlita bailando en la frente. (Vicent, 2014, 116)

En esta obra va tomando lugar, poco a poco, un incipiente interés por lo que ocurría. A su vez, Valencia se presenta como un ámbito conservador, con poco compromiso con los episodios de política estudiantil que ocurrían en Madrid: "La política estaba prohibida. A Valencia apenas llegaban noticias de las luchas estudiantiles que en ese momento libraban en Madrid los universitarios más concientizados". (Vicent, 2014, 116) 
Por último, en esta novela que hemos llamado "de formación" el personaje comienza a creer posible aquel deseo de ser escritor que había guardado en secreto por miedo al ridículo. Esta ambición resulta imprescindible en esta etapa pues, la pérdida de fe amenazaba con perder también al individuo: "Pero realmente esa aspiración no confesada era lo único que me sustentaba por dentro cuando ya mi fe en Dios se iba esfumando y había que ordenar el mundo bajo otra perspectiva" (Vicent, 2014, 103).

Tranvía a la Malvarrosa es, entonces, el relato de ese proceso de ordenamiento del mundo bajo una perspectiva diferente, en la cual nuevos elementos van tomando lugar en una disposición alternativa: se crea un nuevo paradigma tras la crisis con la crianza católica y conservadora. La lectura, al igual que el placer, la política, la escritura, forma parte de este ordenamiento y se puede afirmar que lo guía, lo acompaña.

Si pensamos en los autores que desfilan por las páginas de esta obra, veremos que pertenecen al canon occidental, por lo tanto, son aquellos que esperaríamos encontrar en cualquier biografía de escritor. Podríamos decir que Vicent se refiere a ellos cuando afirma que: "he leído todo lo que debía ser leído en su momento más o menos oportuno" (1996). Sin embargo, el modo en que se refiere a los textos, el momento de su existencia en que los menciona y la forma en que los vincula con las vivencias de esta etapa permite interpretar que esas lecturas están lejos de ser impuestas. Ni Tranvía a la Malvarrosa ni Verás el cielo abierto suponen itinerarios de lectura tradicionales. Incluso, la lectura no es el elemento principal de estos textos, sino uno más, un factor que se suma a muchos otros y que, al igual que ellos, 
resulta formativo y trascendental, pero no necesariamente más importante. Por eso la lectura aparece igualada a otras actividades consideradas menores. Podemos decir que Vicent rechaza el canon impuesto y rechaza las lecturas cuyo "truco" se encuentra rápidamente ${ }^{13}$, que carecen de misterio, que no interpelan al lector. Este es el resultado de un largo camino que comienza con los tebeos, continúa con la relectura de los clásicos y no ha finalizado aún.

El libro como objeto material con el que se vincula estrechamente el lector es revalorizado y destacado en numerosas oportunidades, es por eso que Vicent incluye una crítica a los usos propiciatorios (Musci, 2014, 7), a los que también refiere Chartier a propósito del libro sagrado (2009), en los que no importa la lectura, pero sí la presencia material. En Verás el cielo abierto el uso propiciatorio es negativo, aparece como una oportunidad para el engaño. El libro, al estar cargado simbólicamente, confiere al propietario del mismo o de la biblioteca un estatus intelectual que es apreciado socialmente. Esto, en muchos casos, da lugar al prejuicio, a la sobrevaloración y a apreciaciones equivocadas. El autor refiere un episodio que tuvo lugar al llegar a Madrid. Allí, Manuel elige la pensión en la que vivirá porque ve, al entrar, una biblioteca que ocupa toda la pared. Tiempo después, de forma casual, descubre que esa biblioteca es falsa y decide abandonar el lugar. Vemos aquí dos posibles lecturas: por un lado, la importancia del libro como símbolo de instrucción, de cultura, de intelectualidad, por otro, encontramos una crítica al uso insustancial de ese bien preciado. La crítica

13 Aquí retomo las palabras con las que el autor cierra el artículo "La Literatura y la Lectura como Obras de Arte". 
no es únicamente a Diana, la dueña de aquella casa; el descubrimiento tardío de la "falsa biblioteca" a raíz de un golpe deja ver que Manuel no se había acercado a ella. En este pasaje es posible ver cómo el libro en la biblioteca no siempre es el libro que se lee.

Para concluir, volveremos a la hipótesis que guio el desarrollo de este trabajo: a través del itinerario de lecturas y de la reseńa de los modos de leer que han acompañado su vida de escritor, Manuel Vicent conforma una imagen y ratifica un estilo que se complementa con su labor de periodista y con el resto de sus novelas. La literatura de Manuel Vicent encarna una "representación del mundo a través de los sentidos" ya que, como sostiene Macciuci: "un punto central de su obra es la afirmación de que la verdad reside en lo perceptible por los sentidos, y no en lo que el pensamiento humano pueda alcanzar" (Macciuci, 2013, 13). Lo sensorial, ligado al placer y al disfrute, será un modo de vincularse con el mundo y también con la lectura. Por otro lado, la lectura oficiará de guía para el descubrimiento de ese disfrute.

Las lecturas "confesadas" tienen que ver con la representación que se quiere dar de su vida o de su obra. En el caso de Vicent, la reivindicación de las historietas, tiene que ver con el tipo de lectura que quiere realzar y la actitud hacia la lectura. Al ubicar estos textos marginales en lugar destacado, fundacional, instala la idea de que la elección del texto debe ser guiada por el gusto y no por parámetros impuestos.

Muchos de los pasajes analizados responden a las preguntas referidas al comienzo, aquellas que permitirían, según Lyons, elaborar una historia 
de la lectura: ¿Qué leer? y ¿Cómo leer? Podemos pensar que Vicent ilustra muy bien cómo la lectura involucra al cuerpo en su totalidad. Su biografía de lector se conforma a través de un proceso selectivo que explora diferentes ámbitos escapando de las imposiciones familiares, religiosas, o del canon. En este sentido, el acercamiento al canon es una elección que hace convivir, en el itinerario que hemos comentado, autores canónicos con textos generalmente considerados marginales. Por otro lado, la lectura de los textos canónicos no necesariamente es, a su vez, canónica o guiada por propósitos intelectuales.

Según María Teresa Gramuglio (1992) la conformación de una imagen de escritor incluye cuál es el lugar que él mismo piensa para sí en la literatura y en la sociedad. Manuel Vicent satiriza y rechaza la imagen dominante de escritor (en muchos casos marcadas por la vanidad, la ignorancia y la superficialidad). Por eso, como dice Macciuci, "construye una auto-imagen desertora del tipo del periodista y del escritor, con cualidades "impropias" de ambos" $(2013,11)$. Los textos analizados en el presente trabajo forman parte de esta construcción ya que Manuel Vicent, también como lector, se coloca en lugares inesperados y valoriza textos y modos de leer inesperados.

\section{REFERENCIAS BBBLIOGRÁFICAS}

Alberca, Manuel. "Autoficción de un gozador de placeres efímeros". In: Raquel Macciuci (Ed.). Literatura, soportes, mestizajes. En torno a Manuel Vicent. Número monográfico: Olivar. Revista de Literatura y Cultura Españolas. Número 
monográfico. Año 9, $\mathrm{N}^{\circ} 12.2^{\circ}$ semestre, 2008, pp. 199-216. http://www.memoria. fahce.unlp.edu.ar/library? $\mathrm{a}=\mathrm{d} \& \mathrm{c}=\operatorname{arti} \& \mathrm{~d}=\mathrm{Jpr} 3714$

Balverde, Gerardo. "La educación por los sentidos: memoria y formación en Contra Paraíso y Tranvía a la Malvarrosa de Manuel Vicent”. In: R. Macciuci (ed.). Literatura, soportes, mestizajes. En torno a Manuel Vicent", op. cit., 2008, pp. 233-247. https://www.olivar.fahce.unlp.edu.ar/article/view/OLIv09n12a15/pdf

Chartier, Roger. "Materialidad del texto, textualidad del libro". In: Orbis Tertius, 1(12), 2006, pp. 1-9. http://www.orbistertius.unlp.edu.ar/article/view/ OTv1 1 n12a01/3774

Chartier, Roger. "Lo sagrado, la magia, el sentimiento". In: Agenda cultural. Número 157, agosto, 2009.

De Diego, José Luis. "Literatura y educación. La novela de aprendizaje”. In: Arrabal 5-6, 2007, pp. 293-298.

Gramuglio, María Teresa. "La construcción de la imagen". In: Hector Tizón, Rodolfo Rabanal y María Teresa Gramuglio. La escritura argentina. Santa Fe: Ediciones Universidad Nacional del Litoral, 1992, pp. 37- 64.

Littau, Karin. "Introducción: anatomía de la lectura". In: Littau, K. Teorías de la lectura. Libros, cuerpo y bibliomanía. Buenos Aires: Manantial, 2008, pp. 17-33. (1 ra. ed. Cambridge, 2006. Trad. Elena Marengo).

Lyons, Martyn (2012). Historia de la lectura y de la escritura en el mundo occidental. Buenos Aires: Editoras del Calderón, 2012.

Macciuci, Raquel. "Geografía peninsular y construcciones imaginarias: una lectura de Camino de perfección de Pío Baroja”. In: Facundo Tomás, (ed.). En el país del arte. $2^{\circ}$ encuentro internacional: Literatura y arte en el entresiglos XIX-XX. Valencia: Biblioteca Valenciana, 2002, pp. 209-228.

Macciuci, Raquel. "Contra la clasificación: sobre la literatura de Manuel Vicent". In: Encuentro con Manuel Vicent. Dossier del III Encuentro de Clubs de Lectura de Asturias. Oviedo: Consejería de Educación, Cultura y Deporte, 2013, pp. 6-12. 
Macciuci, Raquel, “Introducción”. In: Vicent, Manuel. Contra Paraíso. Madrid: Cátedra, 2020, 11-221.

Martínez Rus, Ana. "Ni rojos ni ateos: las difíciles relaciones editoriales entre la España franquista y el exilio argentino". In: Kamchatka. Revista de análisis cultural, 7 (Junio), 2016, pp. 11-33.

Musci, Mónica. "Escenas de lectura y escritura en relatos de la posguerra y el franquismo". In: F. Gerhardt, director. Op. Cit.. Vol. V. La Plata: Mariela Sánchez (Ed.). 75 años después: voces y relatos argentinos para la narración de la Guerra Civil española. La Plata: Memoria Académica, 2014, pp. 1-5. http://congresoespanyola.fahce.unlp.edu.ar/iii-congreso-2014/actas-iii-2014/ volumen-5/v05n06Musci.pdf

Vicent, Manuel. "La literatura y la lectura como obras de arte". In: Babelia. El País. Madrid, 30 de noviembre, 1996, p. 24.

Vicent, Manuel. Verás el cielo abierto. Madrid: Alfaguara, 2005.

Vicent, Manuel. Póquer de ases. Madrid: Alfaguara, 2009.

Vicent, Manuel. Tranvía a la Malvarrosa. Madrid: Alfaguara, 2014.

Vicent, Manuel. Travesía literaria y Raquel Macciuci. Iconografía. Madrid: Del Centro Editores, 2017. 